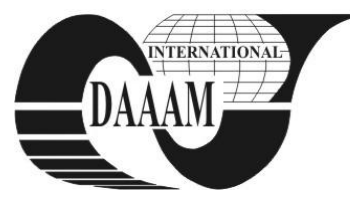

Annals of DAAAM for 2011 \& Proceedings of the 22nd International DAAAM Symposium, Volume 22, No. 1, ISSN 1726-9679 ISBN 978-3-901509-83-4, Editor B. Katalinic, Published by DAAAM International, Vienna, Austria, EU, 2011 Make Harmony between Technology and Nature, and Your Mind will Fly Free as a Bird

Annals \& Proceedings of DAAAM International 2011

\title{
MODEL FOR IMPROVING THE PROCESS APPROACH TO ACHIEVE STRATEGIC GOALS IN INSURANCE COMPANIES: THE CROATIAN CASE
}

\author{
PERONJA, I[van]; VEZA, I[vica] \& KROLO CRVELIN, A[nita]
}

\begin{abstract}
Insurance companies are process-oriented organizations which are continuously faced with pressure to improve business performance such as increased profitability, providing quality services to consumers, but also the return value to shareholders. During the business process management a winning combination proved to be one that allows improving business performance and creating competitive advantage. Although the indicators of global economic crisis conditioned by crisis circumstances show a decline in business activities of insurance companies, it is reasonable to expect better business results in the coming years. Business Process Management should be on top business priorities of the company because of its significance and importance. This paper presents the analysis of the impact of business process management that improves business performance of insurance companies in the Republic of Croatia.
\end{abstract}

Key words: business processes, improving business processes, business process management, strategic goals for insurance companies, insurance companies

\section{INTRODUCTION}

Business process management includes the methods, techniques and tools for the design, standardization, implementation, monitoring and analysis of operational business processes. It includes people, organizations, applications, documents and other information sources (Wesner, Hiatt, Trimble, 1994). Nowadays, when we talk about business process management the question is whether modern management can give answers to the dynamic changes in the environment. What technique, if there is one, should respond to new business requirements and is it possible to use a long-term strategic thinking in strategic management as a solution to current general and specific "bottle necks" in flow of business processes. The answers to these questions have to be rather detailed and have to relate to the effective improvement and process management. It is possible to make the organizations more flexible by applying effective business processes, and it is possible for it to have the optimal responsibility in organizational position on the market. It is possible to improve the quality of the products and the capacity. These should altogether improve the business performance in the organization

So far, various surveys have shown that the importance of business process management can be placed on very top of the of business priorities of the company.

\section{PURPOSE OF THE STUDY}

Analyzed results have been obtained from the empirical part of the paper which consisted of questioning 27 insurance companies which were registered at the Croatian Insurance Bureau in 20010. Business indicators such as the share of total premiums in GDP, per capita premiums, premiums per employee, claims ratio, expense ratio and combined ratio were considered. To improve the process approach in the organization, level of development activities of management business processes, success in the results (performance) of business processes in insurance companies, the characteristics of organizational structure and characteristics of adapting to the environment were studied. Some of the benefits that insurance companies can achieve through BPM are increasing profitability, improving services to consumers, development of more effective sales network, better results in the acceptance of risk, increasing productivity, creating a more flexible system, increasing transparency and integrity of the process, measuring operational efficiency and continuous process improvement. When business processes are improved, flexibility is great because it allows the implementation of improvements at individual, group or organizational level. The fact that improving business processes is a continuous process is its important feature.

\begin{tabular}{cc}
\hline & $\begin{array}{c}\text { Improving business } \\
\text { procesess }\end{array}$ \\
\hline $\begin{array}{c}\text { The degree of change } \\
\text { The frequency of change } \\
\text { The starting point } \\
\text { Duration }\end{array}$ & $\begin{array}{c}\text { Incremental } \\
\text { Continuous }\end{array}$ \\
Involvement & Current business process \\
Common coverage & Approach "bottom up" \\
Risk & Marrowithin the function \\
The primary means & Statistic control \\
Types of changes & Cultural \\
\hline
\end{tabular}

Fig.1. Characteristics of improving business processes

The aim of process orientation is to establish the organizational structure of the process. The organizational form whose core is placed at foundation of key business processes and the flow of business activities is often referred to as the horizontal organization.

A new approach and new way of thinking about the organization that will result in dramatic improvement in efficiency is generally defined as an orientation to business processes (Bosilj Vukšić, Hernaus, Kovačić, 2008).

Business Process Management is a systematic approach to managing and improving the business within an organization with an active, coordinated management of all aspects of the specification, design, implementation, analysis and optimization of business processes to effectively and efficiently achieving business goals (Davis, Brabander, 2007). Within the analyzed insurance companies the lack of orientation process is 
detected. Most of the operations in them are carried out by weakly developed IT support, without a person specifically responsible for the performance of individual processes. There are specific departments or services that are in charge of managing business processes. In these very complex and demanding organizations, which are atypical for modern and flexible process-oriented organization as an insurance companies should be, most business is based on written rules and procedures.The transition process-oriented organizational structure requires additional funds to improve the coordination of cross-functional teams (Sikavica, Novak, 1999).

\section{RESEARCH RESULTS}

Nowadays, there are 27 active insurance companies on Croatian insurance market, five of which are not concerned with mandatory auto liability insurance. Over the years the market has been opened to foreign investors. This has led to a change in the number of insurers. Their ownership structure and diversity of supply has brought various services to consumers. Growth of competitors has brought fierce competition and filtration of market and then "larger" and "more powerful" overtake "smaller" and "weaker". It is interesting that in Croatia the share of premiums for life insurance premiums in total amounts to only $26.4 \%$, which is almost three times less than the average in the European Union. Business data of Croatian Insurers in 2009 say that more than 6.5 million life insurance policy were conducted, as well as over 1.3 million of life insurance policies about 10 billion kunas amounted to charged total gross premiums and the insurance sector employed more than 11,000 employees (Croatian Insurance Bureau). Business Indicators for 2010 show a general decline in business activities in Croatian insurers and this clearly indicates the need to change the course of commercial activities within their own organizations. In the first part of our survey questionnaire, we studied development of activities of business process management through modeling, measurement and monitoring of business processes and establishing metrics, comparison of the effectiveness of different varieties of business process, integration of sectors and harmonization of business processes with business strategy, automation and control of business processes. The mean value, obtained on basis of the results, is 3.33. It indicates that the activities of business process management in the observed companies are moderately developed. In the second part of survey questionnaire, we studied the impact of business process management on business performance. The mean value of the performance processes is 3.46 which is a medium score, so it can be concluded that impact of business process management on business performance in the selected companies is neither good nor bad, but it tends toward good.

In the third part of survey questionnaire we studied how organizational structure is focused on achieving business processes by using teamwork, flexibility in executing tasks, focus on consumers, compensation, mentoring approach, corporate culture and business processes managers. Indicators obtained say that a factor of business process management quite moderately affects organizational structure. In the fourth part of survey questionnaire we studied how business process management affects adaptation to the changing environment through the structure aimed at achieving business process flexibility in performing work assignments, the extent to which cooperation teamwork affects business culture, the extent to which the formal organizational structure fits the business processes managers.

Indicators obtained say that a factor of business process management quite moderately affects flexibility of the organization. The responses obtained from most of the companies ranged between 3.00 to 3.50 , with the mean value of 3.30. By analyzing the results it is concluded that the business process management statistically and practically has a significant impact on the business results of insurance companies.

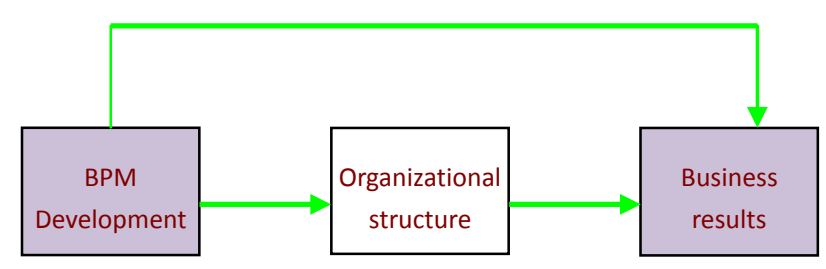

Fig. 2. Graphic presentation of the theoretical model of business process management

\section{CONCLUSION}

Business of insurance companies in the Republic of Croatia has to be adapted to changing market conditions that prevail at financial market. The adaptation strategies of insurance companies must adapt their strategic business goals to the company, but have to be ready to respond to the unexpected market demand. In these responses it is important to choose tactics that will be acceptable to the company in every aspect. Implementing changes should be tactful, moderate and organizationally prepared, which will certainly be easier for those organizations that have developed a process organization. By abandoning existing business practices, improving the flexibility of the organization, eliminating rigid unnecessary laws and regulations that are obstacles in the liberal approach to business, and correcting their own shortcomings in the organization, current operations can be enhanced. The need for fundamental change is either evident at present or will soon be in business orientation. There is a growing awareness, and need for the transformation of existing organizations to the processoriented organizations. Needed changes and attitudes about the necessity of moving towards the process-oriented organization come as a response to new market demands. So we can talk about changing almost every aspect of modern organizations. Apart from a few, Croatian insurance companies are insufficiently process-oriented, which certainly has the effect of poor operating results (the number of concluded policies, the amount of total premiums, the size of claims, increased costs, inefficient human resources, lack of dynamics in creating new products, poor sales of existing products, increased risk in the business, a large number of lawsuits, etc.) which can be minimized in the future. A large number of insurance companies does not have a quality system of information support implemented, nor they are organized or staffed to implement the concept of process, and most often the business processes are not taken into account. Processes take place quietly by themselves, and written documents describing the policies, procedures and accountability in business serve them as a basis for conducting business processes. For all these reasons, companies that do business in the Republic of Croatia can expect major problems in the business, taking into account that the European insurance market is the strongest insurance market in the world.

\section{REFERENCES}

Bosilj Vukšić, V.; Hernaus, T. \& Kovačić, A. (2008). Business process management, Školska knjiga, ISBN 987-95330368-3, Zagreb

Buble, M. (2006). Management Basics, Sinergija, Zagreb

Davis, R. \& Brabander, E. (2007). ARIS Design PlatformGetting Started with BPM, Springer, London

Sikavica, P. \& Novak, M. (1999). Business Organization, Informator, ISBN 86-301-0282-9, Zagreb

Wesner, J.W.; Hiatt, J.M. \& Trimble, D.C. (1994). Winning with Quality, Reading, Addison-Wesley, Bingley 